\title{
The Various Dimensions of Education: A Right of Children and a Duty of Adults
}

\author{
Rossella Marzullo \\ Mediterranea University of Reggio Calabria, Italy.
}

How to cite this paper: Rossella Marzullo. (2021) The Various Dimensions of Education: A Right of Children and a Duty of Adults. Journal of Humanities, Arts and Social Science, 5(1), 40-46.

DOI: $10.26855 /$ jhass.2021.01.006

Received: December 29, 2020

Accepted: January 25, 2021

Published: February 6, 2021

*Corresponding author: Rossella Marzullo, Mediterranea University of Reggio Calabria, Italy.

Email: rmarzullo73@gmail.com

\begin{abstract}
The child has the right to be prepared for a responsible life in a free society, in a spirit of understanding, peace, tolerance, equality of the sexes and friendship between all peoples and ethnic, national and religious groups and people of autochthonous origin. Parents cannot escape the educational challenge, neither from a legal point of view, nor from an ethical and moral one, because the value of education immediately evokes the relationship between the individual and his reality and therefore his ability to be in tune with himself and with others. If education is a right, then it can and must be demanded. Consequently, in the cases where this right appears to be violated, the institutions must help children, in order to be able to replace, to some extent, the figures appointed to educate them and that have proven to be inadequate with respect to such an important task.
\end{abstract}

\section{Keywords}

Education, Human Rights, Parental Responsibility, Juvenile Court

\section{Introduction}

As is known, in his text 'The sources of a science of education', John Dewey elaborates a definition of pedagogical knowledge understood as "an endless circle or spiral, an activity that includes science" (Dewey, 1929). And it is in this way that Dewey's thought, exalting the indefinite nature of pedagogical research, its being continually in progress, has opened to an interdisciplinary approach through the special sources of education, represented by psychology, sociology and anthropology.

Education, in fact, not only has a pedagogical, philosophical, or sociological dimension, but has numerous links with other fields of knowledge including law: it also has its own precise normative connotation, as confirmed by the UN Convention.

Articles 28 and 29 of the Convention on the Rights of the Child expressly qualify education as the right of the child, including it among the provisions to protect the dignity of minors. There is a precise rationale in this choice: the protection of this right has the specific objective of guaranteeing the correct development of the minor's personality, as well as the development of his faculties and his mental and physical attitudes in all their potential.

The aforementioned norm explicitly establishes that the education which minors are entitled to must aim at building a culture of respect for human rights and fundamental freedoms and principles enshrined in the Charter of the United Nations, as well as the respect for their parents, his identity, his language and his cultural values, and the respect for the values of the country where they live, the country they are from and civilizations other than their own.

The child has the right to be prepared for a responsible life in a free society, in a spirit of understanding, peace, tolerance, equality of the sexes and friendship between all peoples and ethnic, national and religious groups and people of autochthonous origin. 
Parents cannot escape the educational challenge, neither from a legal point of view, nor from an ethical and moral one, because the value of education immediately evokes the relationship between the individual and his reality and therefore his ability to be in tune with himself and with others.

If education is a right, then it can and must be demanded. Consequently, in cases where this right appears to be violated, the institutions must help the child, in order to be able to replace, to some extent, the figures appointed to educate and inadequate with respect to such a high task.

In these terms, the right to education refers to social responsibility and, therefore, also to solidarity, in all those cases in which the violation of the law must result in a solicitation to all the forces involved to the restoration of the violated order.

And it is the content of the right to education that must be referred to every time a reflection on the pathological parental relationship is opened, in which the purpose of the person's development is inexorably dissolved in the folds of sub-culture and oppression.

Therefore, what can be the relationship between the child's right to education and the culture of hatred that characterizes criminal organizations?

How can the educational project imagined by Italian and international law be considered fully realized, in a context where parenthood is still, in a decidedly rooted way, conceived as belonging, as a dominion over the smallest who cannot and should not, at the cost of their same lives, escape the rules of the clan?

And how does the state intervene in the face of a serious and irremediable vulnerability of the right to education?

Where the family fails, every other educational agency must be able to re-establish the broken link with the surrounding reality, starting with the Schools, up to the Juvenile Courts and the bodies supporting them, because renouncing to protect the right of children to their existential project, it means condemning them, even before they can choose their destiny - to marginality, emptiness, and to the painful lack of meanings, erased by the absence or distortion of intentionality (Bertolini, 1965; Bertolini, 1988; Husserl, 1936).

\section{The right to education in the peripheries of the world and in the non-places of organized crime}

The difficult relationship that has always characterized the peripheries of the world with the expression of the values of official culture can be felt in all its destructive capacity when it comes to criminal organizations and how they manage to give apparently satisfactory answers to all pockets of marginality, which proliferate in environments marked by economic and cultural decay (Tramma, 2012).

When wondering about how to guarantee the right to education in such contexts, it must be borne in mind that some phenomena are inveterate and stagnant due to the absence of adequate policies aimed the recovery of the social fabric and the enhancement of local resources.

The absence of the state has definitively marked not only the physiognomy of entire areas dominated by organized crime, where the degradation is perceptible to the eye, through the poured concrete that brutalizes landscapes of poignant beauty, but it has also triggered mechanisms of impoverishment, of internal disintegration of the territory which resulted in the inevitable marginalization of these areas with respect to the rest of the territorial context.

The absence of institutions in realities with a high rate of social problems, economic, cultural and housing poverty, has the devastating effect of excluding entire segments of the population from development in the cultural, economic and industrial sense of the territory.

The only form of integration that remains is that with the mafia tradition which presents itself with a vicarious function vis-à-vis the hiding state. For this reason, organized crime finds labor for its activities in these groups of the population.

The problem of the right to education in such contexts is, therefore, twofold: on the one hand, there is the distorted pedagogy of criminal organizations that draw their strength from family ties and therefore push their children to give continuity to the strengthening project of the clan. membership; on the other, there are the conditions of increasing economic poverty and cultural backwardness from which the gangs draw proselytes, who, not finding answers in the institutions, pour into the potentates represented by crime to be able to survive (Marzullo, 2014; Marzullo, 2018).

How is the right to education (denied to children by mafia families or by families who try to support themselves) protected?

We must start from the assumption that our law recognizes the right of minors to a family capable of guaranteeing their rights and if the family fails to exercise this capacity, the consequence cannot correspond to the failure to exercise a right that belongs to the minor, but must correctly involve the responsibilities of the State towards those 
who would otherwise be destined to remain unprotected.

Otherwise the unstoppable path towards an ever-wider protection of the rights of minors would appear to be a sterile exercise of erudition, ranging from their consent to therapies, to ascertaining their awareness with respect to a pathological state, to be heard in their parents' separations, or even to their procedural assistance by a lawyer appointed to protect their specific interests, and not those of their parents, in cases where these interests not only do not converge, but are even opposed.

So, considering that these achievements do not appear to be mere statements of principles with no repercussions on the operational level, all those who interact with children must feel called to take useful and effective actions so that the right to education can also be exercised by children belonging to families of mafia.

In the network of interventions in support of children and adolescents inserted in these contexts, a prominent place is reserved to the school, as a training agency that accompanies the family in the educational project.

The difficulty actually encountered by teachers is well known, because everything that is extraneous to the family unit is expunged in an uncritical and prejudicial manner, but it is also true that the reporting of a discontinuous and problematic relationship with the school universe, as well as the observation of the relationship with peers, or the attitude of the parents in the relationship with the child, can be the first interventions to protect a right that would otherwise be destined not to be exercised or exercisable.

The vigilant action of the school should then find an immediate and strong support in the Juvenile Court, which has the arduous task of evaluating - in accordance with the canons dictated by phenomenological pedagogy (Bertolini, 1965; Bertolini-Caronia, 1993) - the dramas experienced by many children and adolescents who come from these realities.

There can be no possibility of recovery for all those little ones initiated into crime or for reasons of birth or for social exclusion and cultural and economic poverty, without effective action from the institutional world as a whole.

If the action of the institutions were to begin to be stronger, it would produce two orders of consequences in a non-particularly long period of time: the first directly concerns the lives of young people who, through the experiences of estrangement from their families of origin in which they have experienced violence and oppression, can be catapulted into that future evoked by Bertolini (1965) as an initiatory moment of rebirth; the second involves a more purely cultural process, with less evident and less immediate effects, but equally important: the spread of the idea that the state exists, albeit through interventions not accepted by those who suffer estrangement from their children.

In areas where other rules and other codes are in force, where everything that is not perceived as one's own is expunged because it is foreign, being there is of fundamental importance. Being there is the first step towards conquering the possibility of being recognized, and then, in the context of a political and cultural project of profound transformations, even being "respected".

But to be there, we should ask ourselves about the coercibility of the duty to educate that falls upon parents and that is juxtaposed with the right of the minor to be educated.

\section{The juridical foundation of the coercibility of the duty to educate}

The legal basis of the coercion of educating is set forth in art. 30 of the Italian Constitution which gives parents the right and duty to support, instruct and educate their children.

The Fundamental Charter considers these parental prerogatives to be inalienable, so much so that the subsidiary function of the law is expressly codified in the body of the same article in the event that parents are unable to perform their duties.

The duty to educate, therefore, should be considered coercible, albeit in a non-technical way.

In general, the coercibility of the obligation postulates that there are tools to force the holder of that legal position to execute it, but, in the case of the duty to educate, there are no techniques to force a parent to perform this service in favor of their child.

However, the possibility of substituting the law for parents unable to perform the tasks entrusted to them by the legal system is expressly provided, thereby attempting to employ other tools to carry out the educational task which the child cannot be deprived of.

The complex question of the coercibility of the duty to educate requires a reflection on the most authentic meaning of justice. As Edda Ducci (1994, p. 14) wisely suggests, there are moments when "a decisive and clear return to the foundation must be made”. And speaking of coercibility primarily means seeking its foundation: there is no 
coercibility, if there is no justice.

Following the teachings left by the great scholar, the return to the foundation suggests drawing liberally from the Greek world, a precious interlocutor to satisfy "the inevitable need for a solid foundation” (Ducci, 1994, p. 34).

Almost immediately, then, comes the reference to the Platonic definition of justice: it is "the virtue by which with a constant and perpetual will we attribute to each his own” (Plato, Republic, 331E; Plato, Republic, 335E).

The adjective "his" refers to a person's proper right: what belongs to him by reason of an inheritance either natural (in the case of fundamental human rights) or conventional (in the different hypothesis of rights acquired in society), or of one or the other type together.

In Plato's perspective, moral values and political values form a whole. The problem posed by the great philosopher is the following: how can we find an objective justice, superior to the changing interests of men and the relations of power, respectful of objective truth and conscience, the supreme moral demand of man? The answer to these questions lies in the philosopher's idea that man does not live a public life separated from the personal and private sphere; therefore he is authentically a citizen since the polis is seen as the place par excellence where man can truly be himself and find his identity.

Justice as a virtue is again recalled in the beautiful pages of Cicero's De finibus for which: "it never harms anyone, and always produces the natural effect of calming the soul. Iniquity is a source of disturbance: whoever commits an iniquitous act within himself hosts recklessness ... lust ... sloth ... And his act is pursued first by suspicion, then gossip, accuser, judge ... Some then may fear punishment of the gods. But true reason invites people of sound judgment to justice, fairness, loyalty. In the end, the damage caused by injustice is greater than what it gains. Therefore, justice is not desirable by itself either. But because it is more pleasant to be loved, dear ones. Therefore, iniquity must be avoided because of the inconveniences it causes and because it never lets us breathe. Therefore, if virtues are also for pleasure, pleasure is the highest good and living happy is equivalent to living with pleasure" (Cicero, "De finibus bonorum et malorum", V, 23, 67)

At the basis of law (jus), there is therefore justice (justitia). And every right implies the corresponding duty (debitum) of recognition and fulfillment. It is justice, then, that relates men to each other according to relations of rights and duties.

It is characterized by three fundamental elements: otherness, because justice is a social virtue, "ad alium" towards others; it is mandatory, because the law always corresponds to a very specific duty, objectively determined, and binding because it is placed in a relationship of direct correlation with the other's claim that requires respect. So much so that the law is guarded by precise techniques of protection, because man's experience has unfortunately taught that its accomplished realization cannot be considered to be remitted only to the benevolence of the subject who has the duty to respect it; and equality, because justice is the equalizing virtue of the parties, that is, justice is done when the duty fully corresponds to the law and the extent of the due is established.

Justice then places a first constraint, which can be defined as ethical: formal or legal respect for the law is elevated to adhesion and personal commitment. In this case, the external force of the law merges with the conviction and the internal availability of conscience, the enforceability and coercibility of the law is sublimated by the force of love.

In its ethical meaning, long plowed by moral philosophy, justice is the synthesis of the Platonic kalokagathia: being just is the only way to get to Good, to the light that nourishes the soul and leads to true happiness.

However, the structuring of the concept of justice gradually operated by the history of civilization has led to the juxtaposition of the ethical bond with the legal one: the legal bond is external and objective, linked to the force of law, to that which is technically defined cogency, i.e. the possibility of obtaining the fulfillment of an obligation through the institutional force of the law, when it is not spontaneously fulfilled by the one who would be obliged to do so.

Naturally, if one thinks of justice as a philosophical category or as a virtue, in the Platonic or Ciceronian sense, the character of cogency loses all possible meaning. Justice, as a virtue, is much more than a sum of acts; it is a permanent and dynamic disposition of the soul to the highest good, which is sought and desired by freedom (intelligence and will) as personal consistency and fidelity.

Reasoning, therefore, in purely philosophical terms, duty is not born with the law, but with the natural striving for good that the moral conscience recognizes. This is why any disavowal of the rights of others, even if it is not in contrast with the provisions of civil law, is nevertheless contrary to the ethos that refers to the supreme Good: the absolute.

Justice as a virtue, unfortunately, is not the telos of all human society as a whole, otherwise it would be completely unimaginable that man becomes the author of conduct of violence, oppression and domination of the other; just as it would be unimaginable for a parent to abdicate the fundamental task of educating. 
Therefore, the coercibility of every duty is an indispensable instrument of protection that each juridical order must provide, since it is not possible to leave individuals to choose the pursuit of justice as a virtue.

Like any duty, therefore, also that of educating must be able to be demanded by the State and, if in practice it is impossible to impose on mothers and fathers the execution of similar obligations, it is nevertheless possible to activate replacement mechanisms that attempt order violated every time a parent more or less consciously shuns the burdensome and important task of education.

Approaching the issue in the opposite sense, therefore, denying the State a power-duty to intervene in the hypothesis in which the parents do not exercise their obligations on education, would end up in legitimizing injustice: that symmetrical relationship between rights and duties, the equalizing nature of justice as a measure of due, how does it combine with the violation of a right that remains unanswered?

Not only is this not possible, but there is more: no educational project can be said to be effective, if it neglects to contemplate the value of justice; because educating to justice means making the little ones understand that there is an inseparable link between society and the state, between the state-institution and its members.

Justice, understood as "the virtue for which with a constant and perpetual will we attribute to each his own", is almost naturally accompanied by the culture of the common good: if it is right to attribute to each his own, it is equally right to internalize the idea posed at the basis of this principle: every person is equal to another and has the right to the same possibilities; invading the sphere reserved for the other means violating this principle.

In order not to violate it, the word other must be declined in the plural. Only in this way can that "to each his own" of the Platonic definition can be read in its ethical meaning: justice promotes and guarantees the pursuit of the common good. This good implies the duty, for each member, to contribute to respect, enhancement and human development, each according to what is due to him.

Here the duties take shape in the law, which determines the contribution of each to the pursuit of the common good. The solemnity of the value of justice in every human community is a strong awareness of the philosophical, ethical and religious doctrines of all times. This theme so crucial for man recurs in Augustine's thought, so much so that even in the work De civitate dei, he asks himself: "If justice is not respected, what are States if not large criminal organizations? Likewise, what are criminal groups if not small States? The legal power of the me is governed by the chief's command and bound by a social pact, and the loot is divided by an agreeable law" (Augustine, De civitatedei, libro IV, chap. 4).

The duty to educate must then be expressed in the sense of tracing a path in the direction of general justice aimed at the common good; must open a passage within which the subject in training moves independently, without ever forgetting that the most serious form of injustice is the instrumental enslavement of one human being to another, because man is a subject of right in himself, not an object of right for others. As Augustine of Hippo writes: "what makes a man worthy of love is the fact that he is just ... We perceive justice and its beauty (...) with the eyes of the heart, that is, with our intelligence since, in the intimate (of each person ), there is an eye capable of seeing the beauty of justice (Justice)".

And it is with the eye of the heart that many judges are trying to raise more and more the level of attention on the issue of parental responsibility with respect to the duty to educate their children, whose coercibility has increasingly marked features, albeit in the impossibility material to impose a real obligation to carry out the pedagogically correct conduct.

\section{Conclusions}

The general-preventive - and therefore pedagogical-function of certain precepts and certain sanctions, leads us to believe that the judiciary should continue to be interested in the fundamental issue of education, a delicate issue that invites reflection on a difficult "job".

A witness of this is the sentence of the Civil Court of Milan of $4^{\text {th }}$ February 2010, according to which the parents of a group of adolescents, who had perpetrated sexual violence against a twelve-year-old, were sentenced to compensation of 450 thousand Euros.

The fault of these parents, according to the judge, did not lie in not having "attended" their children adequately, but in not having given them an education in the feelings and emotions in the relationship with the other sex.

The novelty of the sentence, which inaugurated an interpretative trend that places the quality of the educational relationship at the center of the evaluation, is precisely in the motivation: the parents were sentenced to compensation not for not having been able to teach their children rules, but for not having been able to give them an education in the feelings and respect of the other. Educating is not a task that can simply be limited to the control or the imposition of 
rules.

The story is part of a scenario that arouses deep concern: that of the so-called "normal" families, or as the psycho-pedagogical literature would define them as "healthy", that is, extraneous to phenomena of deviance or organized crime.

It was the children of unsuspected families, beyond any sociological label, who for more than two years inflicted the worst torture that a human being can experience on a twelve-year-old: the theft of her body and her freedom to decide how to dispose of it, the definitive deprivation of her identity, the loss of herself, of what she was and of what can never be again.

If one wonders about the possible reasons behind the gesture, one realizes that the judges correctly considered the educational vacuum the trigger for the brutality of the pack.

In this sense, the passages of the sentence of the Civil Court of Milan appear illuminating, in that reference was made to the arguments advanced by the parents of the perpetrators of the crime to validate their work as educators.

In fact, the provision states: "The fact that they respect the return time, school performance and Christian values-circumstances that according to the parents of the guilty should be interpreted as symptoms of an education devoted to regularity of life and customs are, on the other hand, "generic circumstances" that take nothing away from the repeatedly committed abuses.

"Education is not only made up of the fundamental indication to comply with the rules, but also of those indications that provide children with the indispensable tools that should be used in relationships, including feelings and sex, with the other. There is, indeed, no trace of this type of education in the behavior of the minors" (Court of Milan, February 4, 2010).

It should make us reflect on the fact that these parents felt they had complied with their task by giving their children rules of a behavioral nature, referable to mere academic performance, or to compliance with the time to come back home.

We should even wonder how could a culture of delegating parenting, that moves within a value-for-money framework, have spread beyond measure, a narcotic parenting that wakes up only when the disease explodes, because no one has ever observed, in this chilling normality, those signals that could have helped understand the direction their children's lives had taken.

The pronouncement is part of this new approach of justice to the problems of society; it is a verdict that perceives the urgent need for the humanization of civil law, and which must leave the old formalistic imprint behind.

If parents have the obligation to educate, even more so the law, understood as a system of rules governing relations between associates, is called to perform this function. And not only with specific reference to the recipients of the rule issued by the code and applied by the magistrate, but above all in a general-preventive key.

In fact, representing oneself as a possible consequence of one's behavior different from that imposed by law, the possibility of being subjected to a sanction, even of a pecuniary nature, can have a dissuasive function that over time, with subsequent stratifications, can penetrate the culture of a country.

It is undoubtedly true that the duty to educate cannot be defined as coercible in a technical sense, but it is also true that the era, in which the educational project can be considered exhausted, is over and where the rules on returning home or school performance are given, since parents have a much broader duty, the failure of which cannot meet the silence of the law.

Education, today more than ever, must be perceived as the fruit of a synergy between institutions. Certainly, the family and the school remain the centers of excellence in the formation of the person, but other bodies must be added to them, including those that perform judicial functions.

As in the present case, after the publication of this verdict, all educators, including less attentive and more distracted parents, were forced to question the quality of education.

And the quality of education is a problem that society has an obligation to raise, in particular, if we are witnessing the growing affirmation of bullying attacks in the herd by minors who act to the detriment of their peers.

Bullying, extortion of money or other types of services, group rapes and ridicule of others' disabilities are the serious symptom of the absence of an education in feelings. The dry indication of the rules, or of the way to follow, is not enough and cannot be enough, without all this being accompanied by the construction of the "first fundamental relationship of love": that between parents and children, that is made up of time, patience and listening (Iori, 2001).

Absent, and often delegating parents, lack of social safety nets that offer valid support to working parents, especially mothers in the first three years of the child's life, family and school policies totally detached from the problems that society presents (Cavana, 2010; Calaprice, 2007), are the basis of the criminogenesis processes that lead to ep- 
isodes such as the one examined by the Court of Milan.

What to do? The phenomenon is complex and therefore does not allow to trace possible solutions without running the risk of excessive simplifications; however, the important aspect is that the issue of education has received the attention of jurisprudence both for the resonance that it can give to the subject, and for the further step towards breaking old systems of protection that are not suitable for restoring the violated order, when there is a vulnus of pedagogical nature at its basis.

The diffusion of a different culture in every segment of society, also through the justice bodies, appears to be a decisive step towards the correct framing of such a complex problem as that concerning the right to education, the compatibility of the latter with certain educational choices and the repercussions of these choices in the social sphere.

\section{References}

Augustine of Hippo. De civitatedei.

Augustineof Hippo. Justice.

Bertolini, P., Caronia, L. (1993). Difficult children, interpretative pedagogy and measures. La Nuova Italia, Florence.

Bertolini, P. (1965). Pedagogy of difficult children. Malipiero, Bologna.

Bertolini, P. (1988). Pedagogic "being”. Grounds and limits of pedagogy as a phenomenologically grounded science. La Nuova Italia, Florence.

Calaprice, S. (2007). Educational training, job and mature age. Training of trainers beyond skills. Laterza, Bari.

Cavana, L. (2010). Phenomenological pedagogy and deviance interpretation. Review of Criminology, Victimology and Security, Book III-N. 3.

Cicero. (n.d.). De finibusbonorum et malorum.

De Luca, C. (2014). Citizenship pedagogy. Anicia, Rome.

Dewey, J. (ed.). (1929). The sources of a science of Education. Translation into Italian 1967. La Nuova Italia, Florence.

Ducci, E. (1994). 'Freed' freedom, Freedom, Law, Laws. Anicia, Rome.

Husserl, E. (1936). Crisis of European and Trascendental Phenomenolgy. translation into Italian (1965) E. Filippini. Il Saggiatore, Milan.

Iori, V. (2001). Pedagogical foundations and family changes. La Scuola, Brescia.

Marzullo, R. (2014). Education, Family, Democracy. Routes of legality, Anicia, Roma.

Marzullo, R. (2018). Rehabilitation pedagogy. Family difficulties, marginality, deviance and organized crime. Anicia, Roma.

Plato. Republic.

Tramma, S. (2012). Legality Illegality. Pedagogic boundaries. Laterza, Rome-Bari. 